\title{
Investigating determinants for patient satisfaction in women receiving epidural analgesia for labour pain: a retrospective cohort study
}

Daryl Jian An Tan ${ }^{1}$, Rehena Sultana ${ }^{2}$, Nian Lin Reena Han ${ }^{3}$, Alex Tiong Heng Sia ${ }^{1,4}$ and Ban Leong Sng ${ }^{1,4^{*}}$ (D)

\begin{abstract}
Background: Epidural analgesia is a popular choice for labour pain relief. Patient satisfaction is an important patientcentric outcome because it can significantly influence both mother and child. However, there is limited evidence in the correlations between clinical determinants and patient satisfaction. We aim to investigate clinical covariates that are associated with low patient satisfaction in parturients receiving labour neuraxial analgesia.

Methods: After institutional ethics approval was obtained, we conducted a retrospective cohort study using electronic and corresponding hardcopy records from 10,170 parturients receiving neuraxial analgesia between the periods of January 2012 to December 2013 in KK Women's and Children's Hospital in Singapore. Demographic, obstetric and anesthetic data were collected. The patient satisfaction scores on the neuraxial labour analgesia was reported by the parturient at 24 to $48 \mathrm{~h}$ post-delivery during the post-epidural round conducted by the resident and pain nurse. Parturients were stratified into one of three categories based on their satisfaction scores. Ordinal logistic regression models were used to identify potential covariates of patient dissatisfaction.

Results: 10,146 parturients were included into the study, of which 3230 (31.8\%) were 'not satisfied', 3646 (35.9\%) were 'satisfied', and 3270 (32.2\%) were 'very satisfied'. Multivariable ordinal logistic regression analysis showed that instrumentassisted vaginal delivery $(p=0.0007)$, higher post-epidural pain score $(p=0.0016)$, receiving epidural catheter resiting $(p<0.0001)$, receiving neuraxial analgesia at a more advanced cervical dilation $(p=0.0443)$, multiparity $(p=0.0039)$, and post-procedure complications headache $(p=0.0006)$, backache $(p<0.0001)$, urinary retention $(p=0.0002)$ and neural deficit $(p=0.0297)$ were associated with patient dissatisfaction. Chinese, compared with other ethnicities $(p=0$. 0104), were more likely to be dissatisfied.

Conclusions: Our study has identified several clinical determinants that were independent associated factors for low patient satisfaction. These covariates could be useful in developing a predictive model to detect at-risk parturients and undertake time-sensitive precautionary measures for better patient satisfaction.
\end{abstract}

Keywords: Epidural analgesia, Labour pain, Patient satisfaction, Quality measures

\footnotetext{
* Correspondence: sng.ban.leong@singhealth.com.sg

1Duke-NUS Medical School, 8 College Road, Singapore 169857, Singapore

${ }^{4}$ Department of Women's Anaesthesia, KK Women's and Children's Hospital,

100 Bukit Timah Road, Singapore 229899, Singapore

Full list of author information is available at the end of the article
}

(c) The Author(s). 2018 Open Access This article is distributed under the terms of the Creative Commons Attribution 4.0 International License (http://creativecommons.org/licenses/by/4.0/), which permits unrestricted use, distribution, and reproduction in any medium, provided you give appropriate credit to the original author(s) and the source, provide a link to the Creative Commons license, and indicate if changes were made. The Creative Commons Public Domain Dedication waiver (http://creativecommons.org/publicdomain/zero/1.0/) applies to the data made available in this article, unless otherwise stated. 


\section{Background}

Epidural analgesia is a popular choice for parturients in addressing labour pains [1-4]. This provides effective pain relief with excellent safety profiles for the mother and fetus [5-7]. Given the high quality of analgesia, labour epidural analgesia could achieve high patient satisfaction [8].

Healthcare professionals have become increasingly more interested in improving long-term outcomes of the care provided. Patient satisfaction in childbirth holds important significance with respect to a patient's outcome and experience. Having a positive experience during childbirth improves the self-esteem of mothers and their confidence in taking care of their newborns [9-11], while a negative experience promotes the risks of developing postnatal depression, poor breastfeeding and, arguably, child neglect and abuse [10-13]. Therefore, it is important to identify potentially modifiable factors which are associated with patient satisfaction so that medical professionals are better prepared to promote a better outcome. Furthermore, patient satisfaction is an indicator of the quality of healthcare; it is imperative for medical professionals to be patient-centric and to tailor therapies to achieve the optimal patient care [14-16]. Achieving high patient satisfaction in labour epidural analgesia is therefore, a reflection of the quality of epidural service delivery. However, there is a paucity of information in the literature that explores the factors influencing patient satisfaction. Hence, the aim of this study is to investigate and identify factors which are associated with low patient satisfaction in parturients receiving labour neuraxial analgesia for labour pain.

\section{Methods}

We conducted a retrospective analysis of the labour neuraxial analgesia electronic database obtained from a single-centre at KK Women's and Children's Hospital, Singapore, between 01 January 2012 and 31 December 2013. The SingHealth Centralised Institutional Review Board approval was obtained prior to the commencement of the study (SingHealth CIRB Ref: 2012/259/D) and the need for informed consent was waived by the CIRB. The electronic records comprising labour neuraxial analgesia forms of 10,170 parturients were retrieved. The electronic database was thoroughly screened for missing and irregular data, and the hardcopies of the corresponding records were reviewed in this event to complete the entries. All the paturients who underwent neuraxial labour analgesia during the study period were included. According to our institution guidelines, all parturients would receive combined-spinal epidural (CSE) analgesia. However, if CSE posed much difficulty to perform, the attending anesthetist might choose to induce epidural analgesia conventionally, without the spinal analgesia component, as the next line of action. Regardless of the induction of analgesia by CSE or conventional epidural technique, analgesia was maintained through an epidural catheter with a regimen consisting of $0.1-0$. $125 \%$ of ropivacaine plus $2 \mu \mathrm{g} / \mathrm{ml}$ of fentanyl with a continuous infusion at a basal rate of up to $10 \mathrm{ml} / \mathrm{h}$.

The demographic data (maternal age, body mass index and ethnicity), obstetric data (parity, pre-epidural cervical dilation and mode of delivery) and anesthetic data (type of neuraxial analgesic technique received, pre- and post-epidural pain scores, occurrence of epidural catheter resiting, total time taken to perform procedure and occurrence of breakthrough pain experienced) were collected. Breakthrough pain was defined as maternal complaints of pain or pressure that required one or more doses of unscheduled supplemental epidural medications [11]. Breakthrough pain was treated by the attending anaesthetist or resident using a typical regimen of $0.2 \%$ ropivacaine $5-10 \mathrm{~mL}$, with or without fentanyl $50 \mathrm{mcg}$. Pre- and post- epidural pain scores were determined using the Visual Analogue Scale. In addition, the occurrence of complications associated with neuraxial analgesia (headache, backache, nausea/vomiting, shivering, itching, urinary retention and neural deficit) was also recorded by a standard postpartum questionnaire. Neural deficit was defined as any parturient complaint of weakness and/or numbness in the lower limbs between 24 to $48 \mathrm{~h}$ post-delivery and urinary retention was defined as the need for presence of indwelling urinary catheter inserted during labour and delivery still present 24 to $48 \mathrm{~h}$ post-delivery.

Patient satisfaction post-delivery on the neuraxial labour analgesia was defined as a numerical rating scale as a percentage (0 to $100 \%$ ) reported by the parturient at 24 to $48 \mathrm{~h}$ post-delivery during the post-epidural round conducted by the resident and pain nurse. Patient satisfaction was routinely asked by the anesthetic service and the parturient was encouraged to provide a score. Parturients with reported satisfaction lower than 80\%, between 80 and $90 \%$, and greater than $90 \%$ were considered as 'not satisfied,' satisfied' and 'very satisfied' respectively. These cut-offs were used as audit standards by the institution. The primary outcome of patient satisfaction was treated as ordinal categorical data.

\section{Statistical analysis}

All demographic, clinical and anesthetic data were summarized with respect to status of patient satisfaction. Continuous variables were summarized either as mean with standard deviation (SD) or median with interquartile range (IQR) and range, and categorical variables were summarized as frequency with proportion. Univariate and multivariable ordinal logistic regression models with cumulative link models were used to identify the 
associations between potential covariates and level of patient's satisfaction. The category of interest in our analysis was parturients who were 'not satisfied'. Associations from the ordinal logistic regression models were characterized using odds ratio (OR) and corresponding $95 \%$ confidence interval ( $95 \% \mathrm{CI})$. Variables with $p$-value $<0.2$ in the univariate model were selected for the multivariable model. Then union of the variables from forward, backward and stepwise method were used to finalize the variable lists in the multivariable model with entry and stay criteria as 0.2 and 0.05 respectively. Then we used likelihood ratio test followed by area under the curve (AUC) to decide the final multivariable model. Then we explored multicollinearity using Pearson's product moment correlation and managed by stepwise variable reduction and quantified by variance inflation factor (VIF). We fit stepwise regression method with clinically meaningful interaction effects with entry and stay criteria as 0.05 and 0.05 respectively. We also compared model with and without interaction effects for performance checking based on Akaike's information criterion (AIC) and AUC from receiver's operating characteristics (ROC) curve. If models with and without interaction effects has similar level of performance then based on principle of parsimony, the model without interaction effects would be selected as the final multivariable model. Significance level was set at 0.05 and all tests were two-tailed. SAS version 9.3 software (SAS Institute; Cary, NC, USA) was used for the analysis.

We had 10,171 eligible patients. Among them 1 patient had incomplete data. Out of these 10,170 patients, 10,146 patients had non-missing information of patient's satisfaction. Our primary objective was to find associated risk factors for "very satisfied" and "satisfied" groups. Peduzzi et al., Concato et al. and Vittinghoff et al. recommended that multivariable logistic regression models should be used with at least 10 events per predictor variable [17-19]. We had 20 clinically meaningful variables to account for in the multivariate model and hence we needed at least $2 * 10 * 20=400$ events in the data. In our data, prevalence of "satisfied" and "very satisfied" group were at least $30 \%$ in each group i.e. we had more than 3000 patients in each "satisfied" and "very satisfied" groups. Our study was adequately powered (>90\%) with 10, 146 patients based on following assumptions: proportion of "satisfied" / "very satisfied" as $30 \%$, OR of 1.5 (or 0.67 ) and alpha or type I error rate as $5 \%$.

\section{Results}

A total of 10,170 parturients were selected for the study. 23 parturients had missing data on patient satisfaction scores and one parturient had data that could not be traced, hence these parturients were not analysed. Among these 10,146 parturients, 3230 (31.8\%), 3646 (35.9\%) and 3270 (32.2\%) were 'not satisfied', 'satisfied' and 'very satisfied' respectively. The flow chart of the study is illustrated in Fig. 1. Table 1 shows the demographics of the parturients.

Univariate and multivariable ordinal logistic regression models are presented in Table 2 to reflect the associations between potential covariates and patient satisfaction with reference to 'very satisfied' category. Univariate ordinal logistic regression model showed that age, ethnicity, mode of child delivery, multiparity, longer time taken to complete neuraxial analgesia, occurrence of epidural catheter resiting, higher post-epidural pain score, and occurrence of post-epidural complications of headache, backache, neural deficit and urinary retention were associated factors for lower patient satisfaction ("not satisfied', 'satisfied' categories).

Multivariable model with interaction and without interaction had similar AUC and AIC values, hence we chose model with main effects only. Multivariable ordinal logistic regression model showed that parturients who were Chinese $(p=0.0104)$ and multiparous $(p=0.0039)$ were more likely to report post-delivery dissatisfaction. Covariates in the intrapartum period that were associated with lower patient satisfaction were parturients who received instrument-assisted vaginal delivery $(p=0.0007)$, resiting

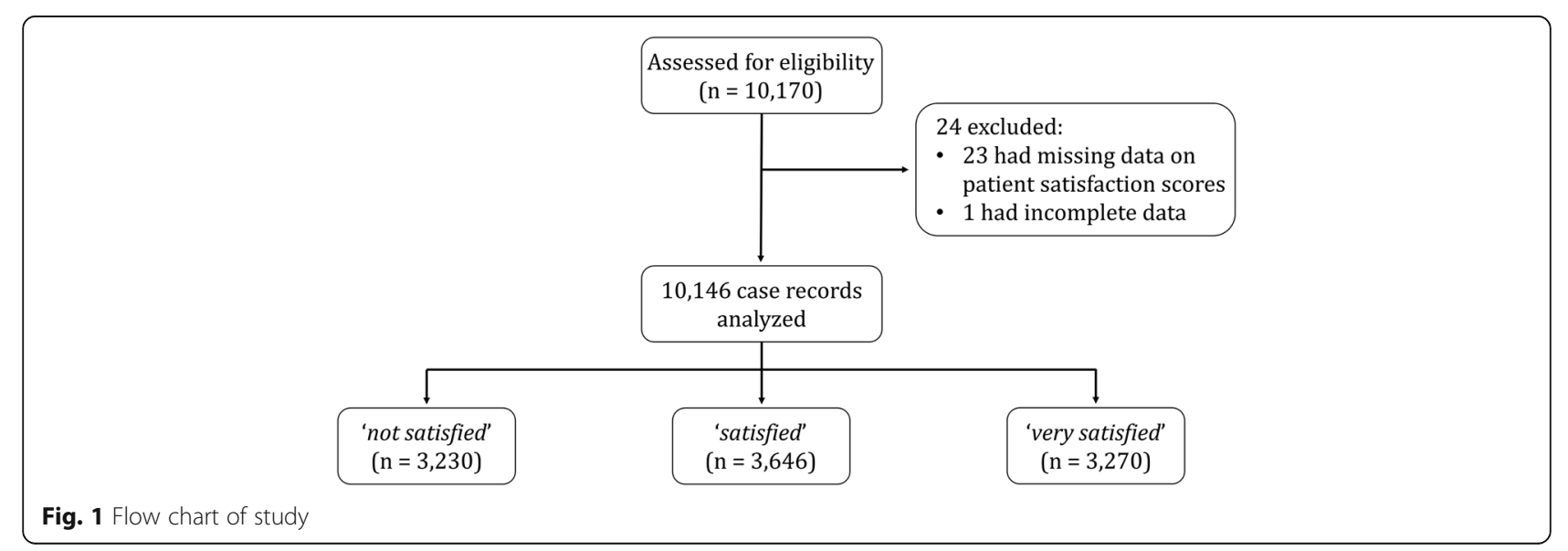


Table 1 Characteristics of 10,146 parturients categorized based on patient satisfaction scores

\begin{tabular}{|c|c|c|c|c|}
\hline & $\begin{array}{l}\text { Not satisfied } \\
(n=3230)\end{array}$ & $\begin{array}{l}\text { Satisfied } \\
(n=3646)\end{array}$ & $\begin{array}{l}\text { Very satisfied } \\
(n=3270)\end{array}$ & $\begin{array}{l}\text { Total } \\
(n=10,146)\end{array}$ \\
\hline Age (years), mean (SD) & $29.8(5.11)$ & $29.9(4.98)$ & $30.1(5.0)$ & $29.9(5.0)$ \\
\hline \multicolumn{5}{|l|}{ Ethnicity, n(\%) } \\
\hline Chinese & $1573(48.7)$ & $1767(48.5)$ & $1481(45.3)$ & $4821(47.5)$ \\
\hline Indian & $387(12.0)$ & $438(12.0)$ & $450(13.8)$ & $1275(12.6)$ \\
\hline Malay & $760(23.5)$ & 861 (23.6) & $756(23.1)$ & $2377(23.4)$ \\
\hline Others & $510(15.8)$ & $580(15.9)$ & $583(17.8)$ & $1673(16.5)$ \\
\hline Body mass index $\left(\mathrm{kg} \cdot \mathrm{m}^{-2}\right)$, mean (SD) & $27.4(5.5)$ & $27.6(8.4)$ & $27.6(4.6)$ & $27.5(6.5)$ \\
\hline \multicolumn{5}{|l|}{ Parity, n(\%) } \\
\hline Nulliparous & $1896(58.7)$ & $2187(60.0)$ & $2077(63.5)$ & $6160(60.7)$ \\
\hline Multiparous & $1335(41.3)$ & $1457(40.0)$ & $1189(36.4)$ & $3981(39.2)$ \\
\hline \multicolumn{5}{|l|}{ Technique of neuraxial analgesia, n(\%) } \\
\hline Combined spinal-epidural & $3053(94.5)$ & $3446(94.5)$ & $3110(95.1)$ & $9609(94.7)$ \\
\hline Epidural & $177(5.5)$ & $200(5.5)$ & $160(4.9)$ & $537(5.3)$ \\
\hline Pre-epidural cervix dilation (cm), mean (SD) & $3.5(1.2)$ & $3.5(1.12)$ & $3.4(1.16)$ & $3.5(1.2)$ \\
\hline Occurrence of epidural catheter resiting, n(\%) & $40(1.2)$ & $18(0.5)$ & $14(0.3)$ & $72(0.7)$ \\
\hline Total time taken to perform procedure (minutes), mean (SD) & $7.3(5.11)$ & $6.9(4.8)$ & $6.7(4.4)$ & $7.0(4.8)$ \\
\hline \multicolumn{5}{|l|}{ Mode of delivery, $\mathrm{n}(\%)$} \\
\hline Normal vaginal delivery & $2371(73.5)$ & $2843(78.2)$ & $2172(66.7)$ & $07,386(73.0)$ \\
\hline Instrument-assisted vaginal delivery & $0370(11.5)$ & $0391(10.8)$ & $0268(8.2)$ & $01,029(10.2)$ \\
\hline Lower-segment caesarean section & $0483(15.0)$ & $0403(11.1)$ & $0816(25.1)$ & $01,702(16.8)$ \\
\hline Pre-epidural pain score, median (IQR [Min - Max]) & $7.0(5-9[0-10])$ & $8.0(5-9[0-10])$ & $7.5(5-9[0-10])$ & $7.0(5-9[0-10])$ \\
\hline Post-epidural pain score, median (IQR [Min - Max]) & $0(0-0[0-9])$ & $0(0-0[0-9])$ & $0(0-0[0-8])$ & $0(0-0[0-9])$ \\
\hline \multicolumn{5}{|l|}{ Reported post-epidural complications, n(\%) } \\
\hline Headache & $26(0.8)$ & $27(0.7)$ & $4(0.1)$ & $57(0.6)$ \\
\hline Backache & $328(10.2)$ & $283(7.8)$ & $123(3.8)$ & $734(7.2)$ \\
\hline Nausea/Nomiting & $318(9.8)$ & 359 (9.8) & $331(10.1)$ & $1008(9.9)$ \\
\hline Shivering & $853(26.4)$ & $900(24.7)$ & $804(24.6)$ & $2557(25.2)$ \\
\hline Itching & $1175(36.4)$ & $1269(34.8)$ & $1155(35.3)$ & 3599 (35.5) \\
\hline Urinary retention & $97(3.0)$ & $79(2.2)$ & $52(1.6)$ & $228(2.2)$ \\
\hline Neural deficit & $14(0.4)$ & $11(0.3)$ & $4(0.1)$ & $29(0.3)$ \\
\hline Occurrence of breakthrough pain, n(\%) & $462(14.3)$ & $517(14.2)$ & $451(13.8)$ & $1430(14.1)$ \\
\hline
\end{tabular}

of epidural catheter $(p<0.0001)$, neuraxial analgesia at a more advanced cervical dilation $(p=0.0443)$, and parturients who experienced higher post-epidural pain score $(p$ $=0.0016$ ). Furthermore, occurrences of post-epidural complications of headache $(p=0.0006)$, backache $(p<0$. $0001)$, urinary retention $(p=0.0002)$ and neural deficit $(p$ $=0.0297$ ) were associated with low patient satisfaction. Interestingly, parturients who received lower-segment caesarean section (LSCS) for child delivery were more likely to report higher patient satisfaction $(p<0.0001)$.

\section{Discussion}

We found that experiencing higher post-epidural pain score, having instrument-assisted vaginal delivery, receiving epidural catheter resiting, and receiving neuraxial analgesia at a more advanced cervical dilation were intrapartum factors associated with low patient satisfaction. Post-procedure complications such as headache, backache, urinary retention and neural deficit were associated with low patient satisfaction. Chinese ethnicity and multiparous parturients were also more likely to report low patient satisfaction.

The knowledge of these clinical associated factors for patient dissatisfaction could be useful to the attending anesthetist to risk-stratify parturients at higher risk of reporting low patient satisfaction and institute strategies to improve clinical outcomes. The importance of patient satisfaction in labour neuraxial analgesia could reflect the quality of analgesia, including the effectiveness and 
Table 2 Univariate and multivariable ordinal logistic regression analyses of covariates of patient dissatisfaction. Status 'very satisfied' was used as the reference category

\begin{tabular}{|c|c|c|c|c|c|c|}
\hline \multirow[t]{2}{*}{ Characteristics } & \multicolumn{3}{|c|}{ Univariate analysis } & \multicolumn{3}{|c|}{ Multivariable analysis } \\
\hline & $\begin{array}{l}\text { Beta coefficient } \\
\text { (SE) }\end{array}$ & OR $(95 \% \mathrm{Cl})$ & $P$ - value & $\begin{array}{l}\text { Beta coefficient } \\
\text { (SE) }\end{array}$ & OR $(95 \% \mathrm{Cl})$ & $P$ - value \\
\hline Age (years) & $-0.01(0.003)$ & $0.992(0.985-0.999)$ & 0.0215 & & & \\
\hline Ethnicity (Ref: Chinese) & & & $0.0060+$ & & & $0.0104+$ \\
\hline Indian & $-0.16(0.06)$ & $0.853(0.761-0.956)$ & 0.0064 & $-0.16(0.06)$ & $0.853(0.760-0.957)$ & 0.0066 \\
\hline Malay & $-0.04(0.05)$ & $0.961(0.878-1.052)$ & 0.3875 & $-0.04(0.05)$ & $0.959(0.876-1.051)$ & 0.3739 \\
\hline Others & $-0.14(0.05)$ & $0.865(0.781-0.959)$ & 0.0057 & $-0.13(0.05)$ & $0.876(0.790-0.971)$ & 0.0118 \\
\hline Mode of delivery (Ref: NVD) & & & $<0.0001+$ & & & $<0.0001+$ \\
\hline Instrument-assisted & $0.16(0.06)$ & $1.179(1.046-1.328)$ & $<0.0001$ & $0.21(0.06)$ & $1.237(1.095-1.398)$ & 0.0007 \\
\hline LSCS & $-0.56(0.05)$ & $0.573(0.518-0.634)$ & $<0.0001$ & $-0.47(0.05)$ & $0.628(0.566-0.697)$ & $<0.0001$ \\
\hline Multiparity (Ref: No) & $0.15(0.04)$ & $1.166(1.083-1.254)$ & $<0.0001$ & $0.11(0.04)$ & $1.119(1.037-1.208)$ & 0.0039 \\
\hline Epidural analgesia (Ref: CSE) & $0.09(0.08)$ & $1.089(0.929-1.277)$ & 0.2913 & & & \\
\hline $\begin{array}{l}\text { Total time taken to perform procedure } \\
\text { (minutes) }\end{array}$ & $0.02(0.004)$ & $1.019(1.012-1.027)$ & $<0.0001$ & & & \\
\hline Pre-epidural cervix dilation (cm) & $0.06(0.02)$ & $1.06(1.027-1.094)$ & 0.0003 & $0.03(0.02)$ & $1.034(1.001-1.067)$ & 0.0443 \\
\hline $\begin{array}{l}\text { Occurrence of epidural catheter resiting } \\
\text { (Ref: No) }\end{array}$ & $0.92(0.23)$ & $2.499(1.587-3.937)$ & $<0.0001$ & $1.02(0.23)$ & $2.775(1.752-4.396)$ & $<0.0001$ \\
\hline Pre-epidural pain score & $-0.002(0.006)$ & $0.998(0.987-1.009)$ & 0.7400 & & & \\
\hline Post-epidural pain score & $0.09(0.03)$ & $1.094(1.024-1.151)$ & 0.0058 & $0.08(0.03)$ & $1.085(1.031-1.142)$ & 0.0016 \\
\hline Occurrence of breakthrough pain (Ref: No) & $0.03(0.05)$ & $1.032(0.931-1.143)$ & 0.5532 & & & \\
\hline \multicolumn{7}{|l|}{$\begin{array}{l}\text { Reported post-epidural complications } \\
\text { (Ref: No) }\end{array}$} \\
\hline Headache & $0.83(0.24)$ & $2.295(1.437-3.664)$ & 0.0005 & $0.83(0.24)$ & $2.296(1.432-3.679)$ & 0.0006 \\
\hline Backache & $0.69(0.07)$ & $1.995(1.737-2.291)$ & $<0.0001$ & $0.61(0.07)$ & $1.840(1.599-2.117)$ & $<0.0001$ \\
\hline NauseaNomiting & $-0.02(0.06)$ & $0.977(0.867-1.102)$ & 0.7076 & & & \\
\hline Shivering & $0.07(0.04)$ & $1.074(0.989-1.166)$ & 0.0912 & & & \\
\hline Itching & $0.03(0.04)$ & $1.034(0.960-1.115)$ & 0.3759 & & & \\
\hline Urinary retention & $0.48(0.12)$ & $1.611(1.263-2.056)$ & 0.0001 & $0.46(0.13)$ & $1.591(1.242-2.039)$ & 0.0002 \\
\hline Neural deficit & $0.79(0.34)$ & $2.205(1.122-4.333)$ & 0.0218 & $0.76(0.35)$ & $2.134(1.077-4.228)$ & 0.0297 \\
\hline
\end{tabular}

NVD normal vaginal delivery, LSCS lower-segment caesarean section, CSE combined spinal-epidural

side effects related to neuraxial analgesia; this could have a bearing on the likelihood of the mother to be more receptive to regional anesthesia in future deliveries. Dharmalingam et al. showed, in a cross-sectional study involving 200 women who have received spinal anesthesia for caesarean section, that 194 (97\%) parturients were satisfied with the spinal anesthesia and 177 (88.5\%) of them would opt for spinal anesthesia in the future for similar surgery if required [20]. This finding also corroborated with other studies $[21,22]$. On the other hand, Charuluxananan et al. showed that patient refusal of neuraxial anesthesia was correlated with a low patient satisfaction score [23]. These demonstrate the relationship between patient satisfaction and the likelihood to receive neuraxial anesthesia in future. However, although analgesic effectiveness contributes to the satisfaction with labor analgesia care, it is not the only contributor to patient satisfaction [24].
Ethnic difference in patient satisfaction was found in our study. Chinese was used as the reference ethnic group because it was the majority of the study population. When compared against Malays, Chinese parturients were less likely to report higher patient satisfaction. Several studies have suggested interethnic differences on the outcomes of epidural analgesia in parturients [2527]. Cultural differences could lead to women perceiving the process of childbirth, coping mechanisms and labour pains differently, thereby leading to the differences in patient satisfaction $[27,28]$. In the non-obstetric setting, it has been shown that pain perception was underestimated in ethnically diverse populations [29, 30]; our study implies a similar picture might be occurring in the obstetric setting in terms of patient satisfaction.

Pain experienced whilst being on labour neuraxial analgesia is a significant association factor for low patient 
satisfaction. Furthermore, Carvalho et al. found that pain experienced during and after caesarean delivery were important patient concerns [31]. Not surprisingly, our results showed that higher post-epidural pain scores experienced by the parturient were associated with lower patient satisfaction. A likely explanation to this could be parturients' expectations of minimal to no pain experienced after receiving neuraxial analgesia, which when they fall short of, result in lower patient satisfaction.

We found that multiparous parturients, when compared with nulliparous parturients, were more likely to be dissatisfied after receiving neuraxial analgesia. This association has not been well studied, and there are differing views with regards to how parity affects patient satisfaction. Koteles et al. has shown in their study that multiparous women were less receptive towards epidural analgesia and were less likely to use it [32]. However, Bélanger-Lévesque et al. has shown in their crosssectional study of 200 mothers that parity could suggest higher patient satisfaction, as prior experience increased their preparation for their current childbirth [33].

Parturients who had instrument-assisted vaginal deliveries were more likely to be dissatisfied as compared to parturients who had normal vaginal deliveries. Our findings were corroborated by a cluster analysis study performed by Rudman et al. that reported negative correlations between patient satisfaction and incidence of instrumentassisted vaginal delivery [34]. It is likely that instrumentassisted vaginal delivery is an indicator of difficult labour, and parturients could have experienced more pain.

Interestingly, we found that parturients with increased cervical dilation at the onset of neuraxial analgesia administration were more likely to be dissatisfied. The initiation of neuraxial analgesia in early labour has been found to be associated with an increased maternal satisfaction and shortened first stage of labour, without increasing the risk of caesarean deliveries [35]. The provision of neuraxial analgesia later in labour could also be associated with lower pain control for a longer period of time prior to receiving neuraxial analgesia.

The occurrence of epidural catheter resiting reported in our study was $0.71 \%$, lower than those reported in previous studies [36, 37]. We found that patients who underwent epidural catheter resiting were more likely to be dissatisfied. As with any invasive procedure, epidural catheter resiting poses considerable distress to parturients and could in itself be perceived as an adverse event in labour epidural analgesia. The repeated procedure also introduces a greater risk of complications in addition to a higher financial cost. Furthermore, the resiting of the epidural catheter is usually performed when the catheter malfunctions or is misaligned. As such, the earlier epidural catheter could have provided inadequate analgesia and resulted in poor pain relief and patient distress, prior to the resiting procedure. Hence, catheter resiting could be a surrogate marker for inadequate analgesia that contributed to a lower patient satisfaction.

The presence of complications after receiving neuraxial analgesia was significantly associated factors relating to low patient satisfaction [22, 38]. It is important to be cognizant of these postoperative complications not only because they could lead to lower patient satisfaction in the current pregnancy, but also increase the tendency of refusing labour neuraxial analgesia in future pregnancies [39]. Of note, the association of post-delivery backache with neuraxial block has not been conclusively determined even though it may be perceived as otherwise [40-42]. Hence, education on post-delivery backache should be included in maternal informed consent as it may potentially help manage parturients' expectations and remove misconceptions.

Nevertheless, we acknowledge the limitations that exist in our study. Patient satisfaction is a multidimensional parameter which could be related to patient, obstetric, anesthetic and psychological factors. Parturients could have reported higher patient satisfaction scores when asked by the anesthetic service as they might have felt obliged to give a higher patient satisfaction score while they were still hospitalized and might potentially require further services from the attending anesthetist $[20,38]$. We tried to mitigate this risk by having patient satisfaction scores obtained in this study 24 to $48 \mathrm{~h}$ after delivery by a different anesthetist who had not been directly involved in the anesthetic care of the parturient. Furthermore, recall bias could be a significant factor. Furthermore, satisfaction is multidimensional and could be influenced by many factors such as family support, environmental changes and mood changes [43], many of which were not accounted for in this study despite the large study population that conferred a good statistical power.

\section{Conclusion}

In conclusion, we found several clinical determinants in the provision of neuraxial analgesia that may have significant influences on patient satisfaction in this study. These determinants are important for the anesthetist to risk-stratify parturients, with further data analytics, as there are time-sensitive opportunities for necessary measures to enhance better patient satisfaction and the quality of holistic care. Further studies are needed to determine if modification of these risk factors affects patient satisfaction scores.

\section{Abbreviations}

Cl: Confidence interval; CIRB: Centralised Institutional Review Board;

CSE: Combined-spinal epidural; IQR: Interquartile range; LSCS: Lower-segment caesarean section; NVD: Normal vaginal delivery; OR: Odds ratio; SD: Standard deviation 


\section{Acknowledgements}

The authors would like to thank Ms. Agnes Teo (Clinical Research Coordinator) and Dr. Kirthinanda Dinoo Suran for their administrative support during this study.

\section{Funding}

The authors acknowledged the funding from the National Medical Research Council, Singapore, Clinical Trials Grant (CTG13feb013) and Centre Grant (NMRC/CG/006/2013).

\section{Availability of data and materials}

All data generated or analysed during this study are included in this manuscript.

\section{Authors' contributions}

DJAT: data collection, data analysis, drafted the manuscript and revised the manuscript critically for important intellectual content. RS: data analysis and was a major contributor in writing the manuscript. NLRH: data analysis and revised the manuscript. ATHS: study design, data analysis and revised the manuscript. BLS: study design, data analysis, revised the article and final approval of the version to be submitted. All authors read and approved the final manuscript.

\section{Ethics approval and consent to participate}

This study was approved by the Singhealth Centralised Institutional Review Board on 12 April 2012 (SingHealth CIRB Ref: 2012/259/D). Informed consent was waived by the CIRB.

\section{Competing interests}

The authors declare that they have no competing interests.

\section{Publisher's Note}

Springer Nature remains neutral with regard to jurisdictional claims in published maps and institutional affiliations.

\section{Author details}

'Duke-NUS Medical School, 8 College Road, Singapore 169857, Singapore. ${ }^{2}$ Centre for Quantitative Medicine, Duke-NUS Medical School, 8 College Road, Singapore 169857, Singapore. ${ }^{3}$ Division of Clinical Support Services, KK Women's and Children's Hospital, 100 Bukit Timah Road, Singapore 229899, Singapore. ${ }^{4}$ Department of Women's Anaesthesia, KK Women's and Children's Hospital, 100 Bukit Timah Road, Singapore 229899, Singapore.

\section{Received: 30 November 2017 Accepted: 27 April 2018}

\section{Published online: 09 May 2018}

\section{References}

1. Hodnett ED. Pain and women's satisfaction with the experience of childbirth: a systematic review. Am J Obstet Gynecol. 2002;186:S160-72.

2. Burnstein $\mathrm{R}$, Buckland $\mathrm{R}$, Pickett JA. A survey of epidural analgesia for labour in the United Kingdom. Anaesthesia. 1999;54:634-40.

3. Bucklin BA, Hawkins JL, Anderson JR, Ullrich FA. Obstetric Anaesthesia workforce survey: twenty-year update. Anesthesiology. 2005;103:645-53.

4. Fanning RA, Briggs LP, Carey MF. Epidural analgesia practices for labour: results of a 2005 national survey in Ireland. Eur J Anaesthesiol. 2009;26: 235-44.

5. Anim-Somuah M, Smyth R, Jones L. Epidural versus non-epidural or no analgesia in labour. Cochrane Database Syst Rev. 2011;12:CD000331.

6. Cambic CR, Wong CA. Labour analgesia and obstetric outcomes. Br J Anaesth. 2010;105:150-60.

7. Reynolds F. Labour analgesia and the baby: good news is no news. Int J Obstet Anesth. 2011;20:38-50.

8. Dickinson JE, Paech MJ, McDonald SJ, Evans SF. Maternal satisfaction with childbirth and intrapartum analgesia in nulliparous labour. Aust N Z J Obstet Gynaecol. 2003;43:463-8.

9. Slade P, MacPherson SA, Hume A, Maresh M. Expectations, experiences and satisfaction with labor. Br J Clin Psychol. 1993;32:469-83.

10. Laurence RJ. Post-traumatic stress disorder after childbirth: the phenomenon of traumatic birth. CMAJ. 1997;156:831-5.

11. Goodman P, Mackey MC, Tavakoli AS. Factors related to childbirth satisfaction. J Adv Nurs. 2004;46:212-9.
12. Thangavelautham STP, Chen H, Assam PN, Sultana R, Han NL, Tan EC, et al. Investigating analgesic and psychological factors associated with risk of postpartum depression development: a case-control study. Neuropsychiatr Dis Treat. 2016:12:1333.

13. Ding T, Wang DX, Qu Y, Chen Q, Zhu SN. Epidural labor analgesia is associated with a decreased risk of postpartum depression: a prospective cohort study. Anesth Analg. 2014;119:383-92.

14. Williams B. Patient satisfaction: a valid concept? Soc Sci Med. 1994;38:509-16.

15. Wu CL, Naqibuddin M, Fleisher LA. Measurement of patient satisfaction as an outcome of regional anesthesia and analgesia: a systematic review. Reg Anesth Pain Med. 2001;26:196-208.

16. Barnett SF, Alagar RK, Grocott MP, Giannaris S, Dick JR, Moonesinghe SR. Patient-satisfaction measures in anesthesia: qualitative systematic review. Anesthesiology. 2013;119:452-78.

17. Peduzzi P, Concato J, Feinstein AR, Holford TR. Importance of events per independent variable in proportional hazards regression analysis II. Accuracy and precision of regression estimates. J Clin Epidemiol. 1995:48:1503-10.

18. Concato J, Peduzzi P, Holford TR, Feinstein AR. Importance of events per independent variable in proportional hazards analysis I. Background, goals, and general strategy. J Clin Epidemiol. 1995;48:1495-501.

19. Vittinghoff $E$, McCulloch CE. Relaxing the rule of ten events per variable in logistic and cox regression. Am J Epidemiol. 2007;165:710-8.

20. Dharmalingam TK, Zainuddin NAA. Survey on maternal satisfaction in receiving spinal Anaesthesia for caesarean section. Malays J Med Sci. 2013;20:51-5.

21. Dove P, Gilmour F, Weightman WM, Hocking G. Patient perceptions of regional anesthesia: influence of gender, recent anesthesia experience, and perioperative concerns. Reg Anesth Pain Med. 2011;36:332-5.

22. Siddiqi R, Jafri SA. Maternal satisfaction after spinal anaesthesia for cesarean deliveries. J Coll Physicians Surg Pak. 2009;19:77-80.

23. Charuluxananan S, Sriprajittichai P, Sirichotvithyakorn P, Rodanant O, Kyokong $\mathrm{O}$. Factors related to patient satisfaction regarding spinal anesthesia. J Med Assoc Thail. 2003;86:S338-43.

24. Richardson MG, Lopez BM, Baysinger CL, Shotwell MS, Chestnut DH. Nitrous oxide during labor: maternal satisfaction does not depend exclusively on analgesic effectiveness. Anesth Analg. 2017;124:548-53.

25. Glance LG, Wissler R, Glantz C, Osler TM, Mukamel DB, Dick AW. Racial differences in the use of epidural analgesia for labor. Anesthesiology. 2007;106:19-25.

26. Toledo P, Sun J, Grobman WA, Wong CA, Feinglass J, Hasnain-Wynia R. Racial and ethnic disparities in neuraxial labor analgesia. Anesth Analg. 2012;114:172-8

27. Atherton MJ, Feeg VD, El-Adham AF. Race, ethnicity, and insurance as determinants of epidural use: analysis of a national sample survey. Nurs Econ. 2004;22:6.

28. Callister LC, Khalaf I, Semenic S, Kartchner R, Vehvilainen-Julkunen K. The pain of childbirth: perceptions of culturally diverse women. Pain Manag Nurs. 2003:4:145-54.

29. Bernabei R, Gambassi G, Lapane K, Landi F, Gatsonis C, Dunlop R, et al. Management of pain in elderly parturients with cancer. JAMA. 1998;279: 1877-82.

30. Todd KH, Deaton C, D'Adamo AP, Goe L. Ethnicity and analgesic practice. Ann Emerg Med. 2000;35:11-6.

31. Carvalho B, Cohen SE, Lipman SS, Fuller A, Mathusamy AD, Macario A. Patient preferences for anesthesia outcomes associated with cesarean delivery. Anesth Analg. 2005;101:1182-7.

32. Koteles J, de Vrijer B, Penava D, Xie B. Maternal characteristics and satisfaction associated with intrapartum epidural analgesia use in Canadian women. Int J Obstet Anesth. 2012;21:317-23.

33. Bélanger-Lévesque MN, Pasquier M, Roy-Matton N, Blouin S, Pasquier JC. Maternal and paternal satisfaction in the delivery room: a cross-sectional comparative study. BMJ Open. 2014;4:e004013.

34. Rudman A, El-Khouri B, Waldenström U. Women's satisfaction with intrapartum care-a pattern approach. J Adv Nurs. 2007;59:474-87.

35. Wong CA, Scavone BM, Peaceman AM, McCarthy RJ, Sullivan JT, Diaz NT, et al. The risk of cesarean delivery with neuraxial analgesia given early versus late in labor. N Engl J Med. 2005;352:655-65

36. Pan $\mathrm{PH}$, Bogard TD, Owen MD. Incidence and characteristics of failures in obstetric neuraxial analgesia and anesthesia: a retrospective analysis of 19,259 deliveries. Int J Obstet Anesth. 2004;13:227-33.

37. Paech MJ, Godkin R, Webster S. Complications of obstetric epidural analgesia and anaesthesia: a prospective analysis of 10995 cases. Int J Obstet Anesth. 1998;7:5-11. 
38. Rhee WJ, Chung CJ, Lim YH, Lee KH, Lee SC. Factors in patient dissatisfaction and refusal regarding spinal anesthesia. Korean J Anesthesiol. 2010;59:260-4.

39. Ahmad I, Afshan G. Knowledge and attitudes of Pakistani women towards anaesthesia techniques for caesarean section. J Pak Med Assoc. 2011;61:359.

40. Russell R, Dundas R, Reynolds F. Long term backache after childbirth: prospective search for causative factors. BMJ. 1996;312:1384-8.

41. Horlocker TT, McGregor DG, Matsushige DK, Schroeder DR, Besse JA. A retrospective review of 4767 consecutive spinal anesthetics: central nervous system complications. Anesth Analg. 1997;84:578-84.

42. Fyneface-Ogan $\mathrm{S}$, Mato CN, Ogunbiyi OA. Comparison of maternal satisfaction following epidural and general anaesthesia for repeat caesarean section. East Afr Med J. 2009:86:551-7.

43. Robinson PN, Salmon P, Yentis SM. Maternal satisfaction. Int J Obstet Anesth. 1998:7:32-7.

Ready to submit your research? Choose BMC and benefit from:

- fast, convenient online submission

- thorough peer review by experienced researchers in your field

- rapid publication on acceptance

- support for research data, including large and complex data types

- gold Open Access which fosters wider collaboration and increased citations

- maximum visibility for your research: over $100 \mathrm{M}$ website views per year 